\title{
Blending Education and Guidance to Enrich Cognitive Development: An approach to Boost Students' Interest in Education
}

\author{
Jagriti Mehta $^{1 *}$, Kiran Jyoti Kaur ${ }^{1}$, Shruti Marwaha ${ }^{2}$, Anil Kishore Sinha ${ }^{3}$ \\ ${ }^{1}$ Research Scholar, Department of Anthropology, Panjab University, Chandigarh- 160014, India \\ ${ }^{2}$ Researcher, Department of Anthropology, Panjab University, Chandigarh- 160014, India \\ ${ }^{3}$ Professor, Department of Anthropology, Panjab University, Chandigarh- 160014, India
}

\author{
DOI: $10.36348 /$ jaep.2022.v06i01.006 \\ | Received: 11.12.2021 | Accepted: 25.01.2022 | Published: 29.01.2022 \\ *Corresponding author: Jagriti Mehta \\ Research Scholar, Department of Anthropology, Panjab University, Chandigarh- 160014, India
}

\section{Abstract}

Student learning must be developmentally appropriate and compatible with students' levels of intellectual, physical, social, and emotional development. Variety of instructional materials can be used during the teaching- learning process to make learning enjoyable and student centered. The in-hand longitudinal study was conducted on a sample of 60 school going students, between 10 and 14 years of age, of Yadavindra Public School (YPS), Patiala, Punjab, India from 2016 to 2017, in order to analyze and record the effect of the regular intervention of customized education and guidance on the cognitive development and academic achievement of students. It was notified that if the students are taught according to their respective learning nature, they will grasp much easily and develop their interest in studies. Through the in-depth study, it was inferred that the interest in studies developed among those receiving education through the methods linking directly to their strength and dominant learning style.

Keywords: Cognitive development, Academic achievement, Customized education, Intervention, Guidance, Natural learning style.

Copyright (C) 2022 The Author(s): This is an open-access article distributed under the terms of the Creative Commons Attribution 4.0 International License (CC BY-NC 4.0) which permits unrestricted use, distribution, and reproduction in any medium for non-commercial use provided the original author and source are credited.

\section{INTRODUCTION}

Anthropology applied to education constitutes a broad domain with roots and continuing connections to disciplines like linguistics, psychology, sociology and philosophy (Henze, 2020). The psychological aspect of the culture and personality school of thoughts in anthropology and later in cognitive anthropology have had a direct relevance to educational issues and child development (Greenman, 2005). A child has the capacity to develop all kinds of intelligence to a reasonably high level. It is asserted that applying the multiple intelligence method of teaching can help encourage students' involvement in the process of language acquisition. Spatial intelligence deals with spatial judgment and the ability to visualize with the mind's eye. Linguistic intelligence has to do with words, spoken or written. Logical intelligence deals with logic, abstractions, reasoning, and numbers. Bodily-kinesthetic: The core elements of the bodilykinesthetic intelligence are control of one's bodily motions and the capacity to handle objects skillfully. Musical intelligence deals with sensitivity to sounds, rhythms, tones, and music. Interpersonal intelligence includes interaction with others. Intrapersonal intelligence has to do with introspective and selfreflective capacities. Naturalistic intelligence deals with nature, nurturing and relating information to one's natural surroundings.

All these eight intelligences are independent and they develop at different times to different degrees in different individuals. However, they are closely related. Learner-centered classrooms to be created for success-oriented students. Creating an active learning environment thereby providing with opportunities for hands-on learning and construct their own knowledge. They should be allowed to work with concepts in different ways, including multisensory activities that enable them to see, hear, feel, smell, and even taste concepts. Formal education, which is recognized as schooling, constitutes a part of the anthropology and education domain (Greenman, 2005). The anthropological constructs and methods are inherently applied to the complex institution of education with the schooling dimension largely anchored in psychology. 
The present study covers the psychological aspects that influence how individuals learn in order to understand the role of education and guidance through intervention in enriching cognitive development.

\section{Review of Literature / Statement of the Problem}

It becomes essentially important to review the existing literature in order to ensure the suitability and relevance of the topic under study. In regard to the same various related studies were reviewed. As narrated by Toffler (1972), the illiterate of the 21st century, will not be those individuals who cannot read and write, but those who cannot learn, unlearn and relearn. Siegler (1983) while referring to Piagetian concept of cognitive development had claimed that cognition is connected with mental process of understanding. Cognitive development refers especially to the mental development of child. With the passage of time the experiences of child are changed and increased this is called the process of cognitive development. In this concern, James (1987) had also mentioned that education must develop the abilities for engaging children in constructive and conducive activities. Kruger and Dunning (1999) has elaborated relevance of perfect estimation and that poor performers often show little insight into the shortcomings in their performance, presumably because they suffer a double curse. Deficits in their knowledge prevent them from both producing correct responses and recognizing that the responses they produce are inferior to those produced by others. Alexander (2001) found high correlation of intelligence and creativity on the learning nature of students. Boylan (2009) in an eminent study found that when the children are taught via teaching style corresponding to their learning nature, the output is favourable as compared to teaching everyone in same and traditional manner. Cassidy et al., (2011) found the effectiveness of automated multiple-exemplar relational training in raising children's general intellectual skills. Blagg (2012) found that both teacher and pupil outcomes can be elevated by combining innovative and traditional experimental techniques of teaching specifically in relation to the learning style and interest of the learners. Endorsing the same, Francis (2012) found that imparting instructions through learning and thinking styles of students improve their academic achievement. Pritchard (2013) confirmed that the learning process can be improved by implementing the educational instructions with respect to the learning styles of students in the classroom. Lunenburg and Lunenburg (2014) claimed that the educational system is heavily biased toward linguistic modes of instruction and assessment and, to a somewhat lesser extent, toward logical-mathematical modalities as well. Since not all learners possess equally strong linguistic intelligence, so education becomes difficult for them. Results indicated that Gardner's multiple intelligences to help improve identify and improve learning outcomes. Kerry (2015) suggested that there is a need for thinking and higher-order cognition to be made central to curriculum planning, and to classroom learning and teaching. Derakhshan \& Faribi (2015) confirmed the positive effects of multiple intelligences on learning. Bas and Beyhab (2017) found that teaching through multiple intelligences enhanced learning among students. Gardner (2017) found that selective attention among students can be fostered. Morewedge et al., (2015) explained that decision making can be improved by training and intervention. Hall (2018) suggested that the creativity is a vital factor in students' performance. Jung and Chang (2017) have claimed that multiple intelligences can improve thinking skills and creativity. Shearer and Karanian (2017) determined there is robust evidence that each intelligence possesses neural coherence that is clear, distinct and aligned with accepted cognitive neural correlates. Implications for using MI theory as a bridge between cognitive neuroscience and instruction were also claimed. Kupers et al., (2019) suggested that education lays a great hand in developing children's creativity. Barros et al., (2019) suggested that informational processes contribute more to the self-controlled feedback learning advantage, relative to motivational contributions and eventually enhance learning. Krannich et al., (2019) found that being overchallenged had a negative impact on academic self-concept. Lower academic self-concept, in turn, was associated with decreased career aspirations.

Students should be made to learn differently in a classroom rather than passively listening to the teachers' lecture and receiving information. Traditionally schools and education were cognitively based merely on verbal and logical intelligences as most of the schools used only these ways to teach. However, Gardner (1983) in his Multiple Intelligence theory propagated that children differ in their abilities, learning styles and interests. Hence, these differences must be acknowledged and nurtured in school at every stage. An awareness of multiple Intelligences and multiple intelligence approach of curriculum transaction could be given at schools, which would help students identify their dominant intelligence and teachers to plan guidance sessions to meet the diverse student community.

In view of the above, the research study inhand was found to be vital and significant owing to its exclusive focus on impact of education and guidance to enrich cognitive development among children. It will also boost students' interest in education. The results and findings can aid in the implementation of these finding in the educational system. Although ample research studies have been conducted on topics, but very less such studies were found to be conducted having emphasized the influence of both the vitals i.e. the education tasks as well as the guidance on the cognitive development of children. 


\subsection{Objectives}

2.1.1 To compare the intelligence quotient of respondents before and after intervention.

2.1.2 To compare the focus factor of respondents before and after intervention.

2.1.3 To compare the decision making ability of respondents before and after intervention.

2.1.4 To compare the academic marks of respondents before and after intervention.

\section{RESEARCH METHODOLOGY}

The present in-depth quintessential research is an allying paradigm, aimed to analyze and record the effect of the regular intervention of customized education and guidance on the cognitive development and academic achievement of students.

\subsection{Sampling}

The in-hand longitudinal study was conducted on a sample of 60 school going students between 10 and 14 years of age, including girls as well as boys. The respondents selected were students of Yadavindra Public School (YPS), Patiala, Punjab, India. The data were collected from the year 2016 to the year 2017.

\subsection{Tool for Data Collection}

Cognitive Ability Scale developed by Nanda et al., (2015) was used to assess the intelligence quotient, focus factor and decision-making ability. Multiple intelligence scale developed by Marwaha and Seth (2017) was used to assess the primary learning style. Besides, academic tests were used to find academic test marks. Proper guidance and help in understanding were provided where and when required during the intervention.

\subsection{Procedure}

At the initial stage, rapport was built with respondents. The prior consent of the school authority as well as of respondents was taken. Following this, the Cognitive Ability Scale was used to assess the intelligence quotient, focus factor and decision-making ability. Multiple intelligence scale was used to assess the primary learning style. Besides, academic tests were used to find academic test marks. All the subjects were assessed and based on their performance on cognitive ability assessment and academic performance, they were categorized into four basic groups termed as group $\mathrm{A}, \mathrm{B}, \mathrm{C}$ and D on the basis of the pretest. Group A comprised of those students who were found to be cognitive bright as well as academic bright. Group B included sample who were cognitive bright but academic weak students. Group $\mathrm{C}$ included sample who were cognitive weak but academic brilliant students. Group D included sample that was cognitive weak as well as weak in academics.

Table 1: Research Design

\begin{tabular}{|l|l|l|}
\hline Total sample $(\mathrm{n}=60)$ & Cognitive Bright & Cognitive Weak \\
\hline Academic Bright & Group A $(\mathbf{n = 1 4})$ & Group C $(\mathbf{n = 1 2})$ \\
\hline Academic Weak & Group B $(\mathbf{n = 1 6})$ & Group D $(\mathbf{n = 1 8})$ \\
\hline
\end{tabular}

Table 2: Sampling

\begin{tabular}{|c|c|c|c|c|c|c|c|}
\hline \multicolumn{2}{|l|}{ Group A } & \multicolumn{2}{|l|}{ Group B } & \multicolumn{2}{|l|}{ Group C } & \multicolumn{2}{|l|}{ Group D } \\
\hline Experimental & Control & Experimental & Control & Experimental & Control & Experimental & Control \\
\hline $\mathrm{n}=7$ & $\mathrm{n}=7$ & $n=8$ & $n=8$ & $n=6$ & $n=6$ & $n=9$ & $\mathrm{n}=9$ \\
\hline \multicolumn{8}{|l|}{ Pre-test } \\
\hline Intervention & $\begin{array}{l}\text { No } \\
\text { Intervention }\end{array}$ & Intervention & $\begin{array}{l}\text { No } \\
\text { Intervention }\end{array}$ & Intervention & $\begin{array}{l}\text { No } \\
\text { Intervention }\end{array}$ & Intervention & $\begin{array}{l}\text { No } \\
\text { Intervention } \\
\end{array}$ \\
\hline
\end{tabular}

As clear from Table 2, once the sample was categorized into these 4 basic groups, they were further divided purposively into sub groups as experimental and control groups. Boys as well as girls between 10 to 14 years of age were included. In form of intervention, customised education (worksheets) as well as guidance was given to subjects in experimental groups. The worksheets were based on the natural learning style and intelligence of each subject. Subjects were instructed to attempt 2 worksheets daily. Further guidance sessions were given to the subjects. The intervention continued for six months. On the contrary, no intervention was provided to the control groups. Later, the post test was conducted on all the subjects in each group. Data was compiled and analyzed.

\section{RESULTS AND DISCUSSION}

The data collected was analyzed using the SPSS to draw the desired inferences. After collecting the data, it was organized and analyzed to draw the statistical inferences. SPSS software was for statistics. Descriptive statistics were calculated and t-test was conducted to compare the experimental and control groups in terms of their intelligence quotient, focus factor, decision making ability and academic marks before and after intervention. 
Table 3: Variation in the intelligence quotient of subjects

\begin{tabular}{|l|l|l|l|l|l|l|l|l|}
\hline Intelligence Quotient & Group A & Group B & \multicolumn{2}{l|}{ Group C } & \multicolumn{2}{l|}{ Group D } \\
\hline Group & Ex & Co & Ex & Co & Ex & Co & Ex & Co \\
\hline Pre-test & 128.85 & 129.45 & 126.65 & 127.95 & 88.50 & 88.95 & 89.50 & 90.00 \\
\hline Post-test & $132.00^{*}$ & 129.65 & $130.50^{*}$ & 128.15 & $99.45^{*}$ & 89.00 & $97.50^{*}$ & 90.10 \\
\hline
\end{tabular}

Where Ex stands for Experimental Group and Co stands for Control Group

*Statistically significant differences

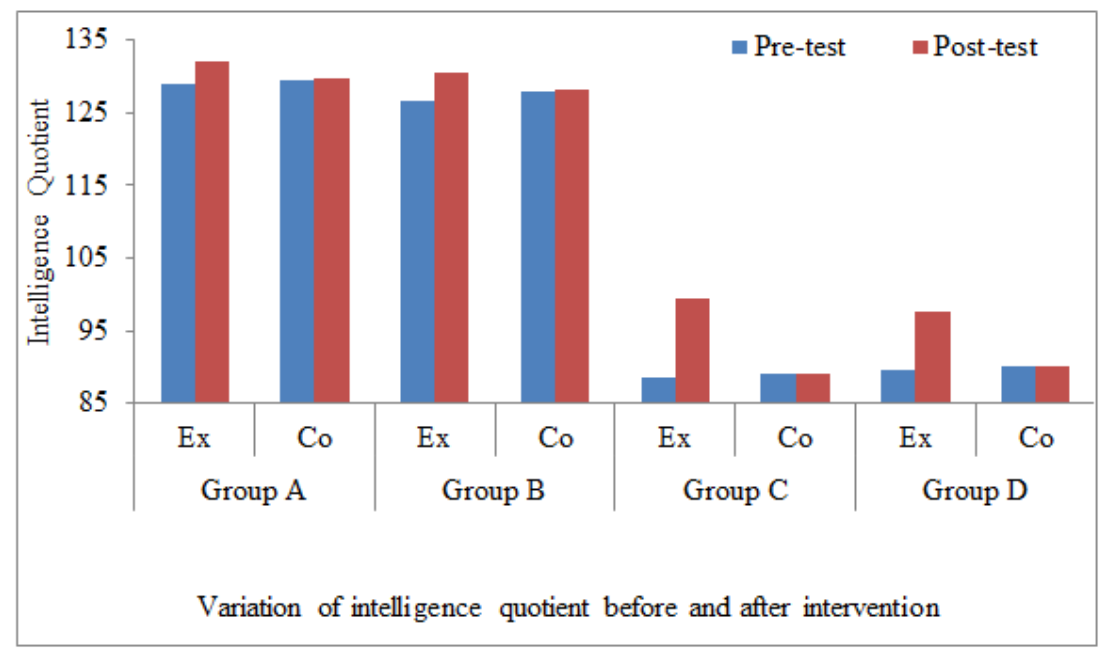

Fig 1: Variation of intelligence quotient before and after intervention

Where Ex stands for Experimental Group and Co stands for Control Group

It is evident from the Table 3 that the intelligence quotient of the subjects in experimental Group A was 128.85 in the pretest which inclined to 132 after the intervention. The difference was found to be significant. Further, it was observed that the intelligence quotient of the subjects in the control Group A was 129.45 that showed no significant change even after the intervention. Moreover, the intelligence quotient of the subjects in experimental Group B was 126.65 in the pretest which inclined to 130.5 after the intervention. The difference was found to be significant. Further, it was observed that the intelligence quotient of the subjects in the control Group B was 127.95 that showed no significant change even after the intervention. Moreover, the intelligence quotient of the subjects in experimental Group $C$ was 88.5 in the pretest which inclined to 99.45 after the intervention. The difference was found to be significant. Further, it was observed that the intelligence quotient of the subjects in the control Group $\mathrm{C}$ was 88.95 that showed no significant change even after the intervention. Moreover, the intelligence quotient of the subjects in experimental Group D was 89.5 in the pretest which inclined to 97.5 after the intervention. The difference was found to be significant. Further, it was observed that the intelligence quotient of the subjects in the control Group D was 90 that showed no significant change even after the intervention.

Table 4: Variation in the focus factor of subjects

\begin{tabular}{|l|l|l|l|l|l|l|l|l|}
\hline Focus Factor & \multicolumn{2}{|l|}{ Group A } & \multicolumn{2}{l|}{ Group B } & \multicolumn{2}{l|}{ Group C } & \multicolumn{2}{l|}{ Group D } \\
\hline Group & Ex & Co & Ex & Co & Ex & Co & Ex & Co \\
\hline Pre-test & 108.85 & 109.10 & 107.75 & 108.00 & 65.00 & 65.50 & 64.50 & 64.50 \\
\hline Post-test & $136.50 *$ & 109.00 & $130.50^{*}$ & 108.50 & $102.50^{*}$ & 67.25 & $99.75^{*}$ & 65.00 \\
\hline
\end{tabular}

Where Ex stands for Experimental Group and Co stands for Control Group

*Statistically significant differences 


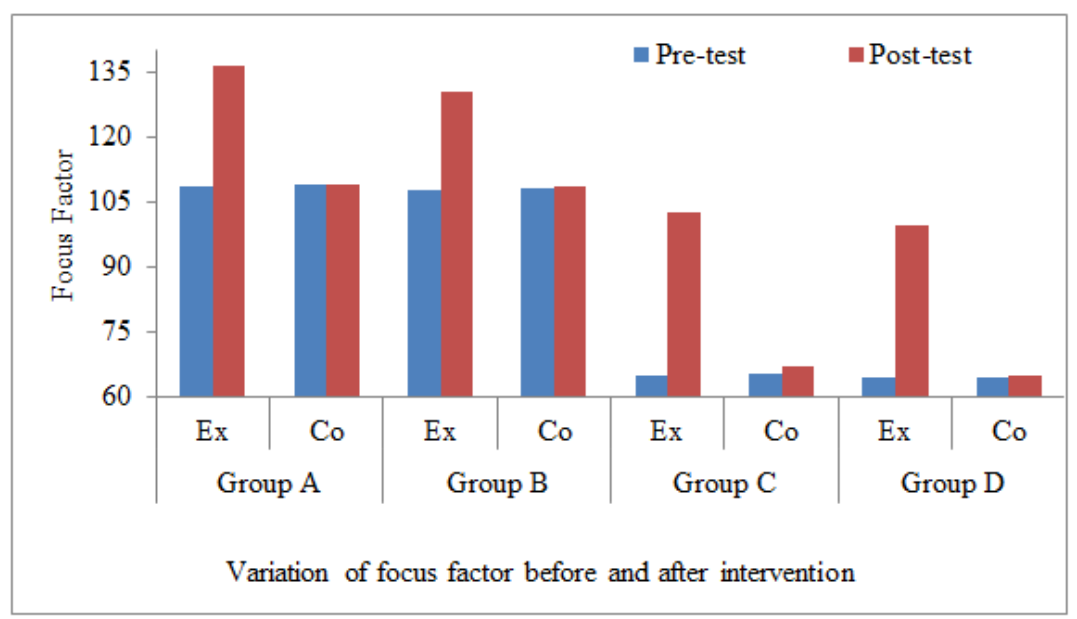

Fig 2: Variation of focus factor before and after intervention

Where Ex stands for Experimental Group and Co stands for Control Group

It is evident from the Table 4 that the focus factor of the subjects in experimental Group A was 108.85 in the pretest which inclined to 136.5 after the intervention. The difference was found to be significant. Further, it was observed that the focus factor of the subjects in the control Group A was 109.1 that showed no significant change even after the intervention. Moreover, the intelligence quotient of the subjects in experimental Group B was 107.75 in the pretest which inclined to 130.5 after the intervention. The difference was found to be significant. Further, it was observed that the focus factor of the subjects in the control Group
B was 108 that showed no significant change even after the intervention. Moreover, the intelligence quotient of the subjects in experimental Group $\mathrm{C}$ was 65 in the pretest which inclined to 102.5 after the intervention. The difference was found to be significant. Further, it was observed that the focus factor of the subjects in the control Group $\mathrm{C}$ was 65.5 that showed no significant change even after the intervention. Moreover, the intelligence quotient of the subjects in experimental Group D was 64.5 in the pretest which inclined to 99.75 after the intervention. The difference was found to be significant. Further, it was observed that the focus factor of the subjects in the control Group D was 64.5 that showed no significant change even after the intervention.

Table 5: Variation in the decision making ability of subjects

\begin{tabular}{|l|l|l|l|l|l|l|l|l|}
\hline Decision Making Ability & \multicolumn{2}{l|}{ Group A } & \multicolumn{2}{l|}{ Group B } & \multicolumn{2}{|l|}{ Group C } & \multicolumn{2}{|l|}{ Group D } \\
\hline Group & Ex & Co & Ex & Co & Ex & Co & Ex & Co \\
\hline Pre-test & 0.74 & 0.75 & 0.75 & 0.76 & 0.39 & 0.40 & 0.38 & 0.39 \\
\hline Post-test & $0.85^{*}$ & 0.76 & $0.84^{*}$ & 0.77 & $0.64 *$ & 0.41 & $0.61^{*}$ & 0.39 \\
\hline
\end{tabular}

Where Ex stands for Experimental Group and Co stands for Control Group *Statistically significant differences

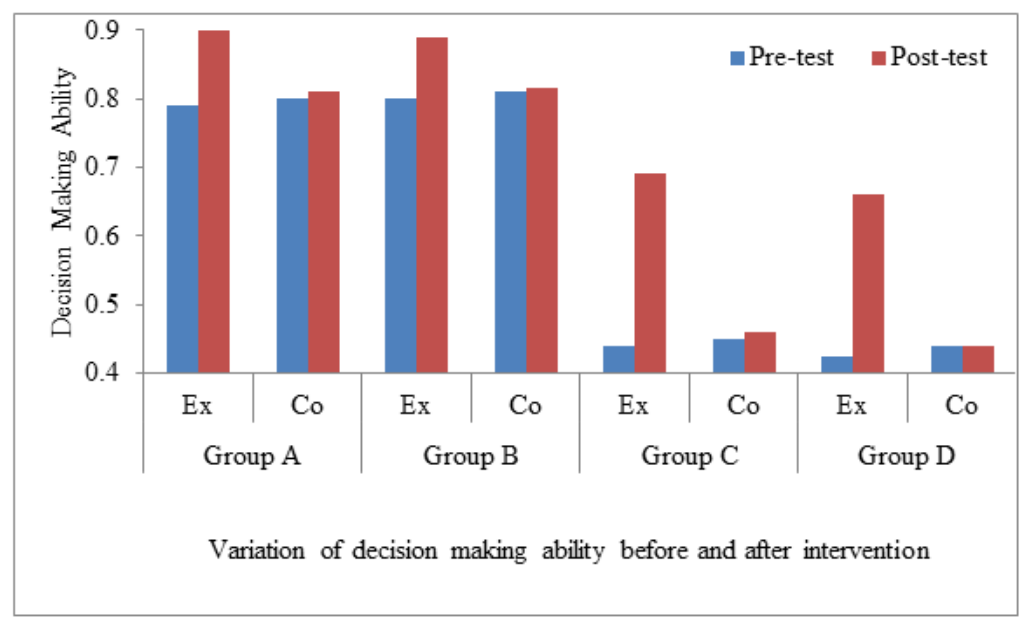

Fig 3: Variation of decision making ability before and after intervention 
Where Ex stands for Experimental Group and Co stands for Control Group

It is evident from the Table 5 that the decision making ability of the subjects in experimental Group A was 0.74 in the pretest which inclined to 0.85 after the intervention. The difference was found to be significant. Further, it was observed that the decision making ability of the subjects in the control Group A was 0.751 that showed no significant change even after the intervention. Moreover, the intelligence quotient of the subjects in experimental Group B was 0.75 in the pretest which inclined to 0.84 after the intervention. The difference was found to be significant. Further, it was observed that the decision making ability of the subjects in the control Group B was 0.76 that showed no significant change even after the intervention. Moreover, the intelligence quotient of the subjects in experimental Group $\mathrm{C}$ was 0.39 in the pretest which inclined to 0.64 after the intervention. The difference was found to be significant. Further, it was observed that the decision making ability of the subjects in the control Group C was 0.4 that showed no significant change even after the intervention. Moreover, the intelligence quotient of the subjects in experimental Group D was 0.375 in the pretest which inclined to 0.61 after the intervention. The difference was found to be significant. Further, it was observed that the decision making ability of the subjects in the control Group D was 0.39 that showed no change even after the intervention.

Table 6: Variation in the academic achievement of subjects

\begin{tabular}{|l|l|l|l|l|l|l|l|l|}
\hline Academic Marks & Group A & \multicolumn{2}{l|}{ Group B } & \multicolumn{2}{l|}{ Group C } & \multicolumn{2}{l|}{ Group D } \\
\hline Group & Ex & Co & Ex & Co & Ex & Co & Ex & Co \\
\hline Pre-test & 87.00 & 87.00 & 57.70 & 58.50 & 86.50 & 86.00 & 49.50 & 49.00 \\
\hline Post-test & $94.15^{*}$ & 87.50 & $62.00^{*}$ & 58.90 & $91.00^{*}$ & 87.15 & $58.00^{*}$ & 49.75 \\
\hline
\end{tabular}

Where Ex stands for Experimental Group and Co stands for Control Group *Statistically significant differences

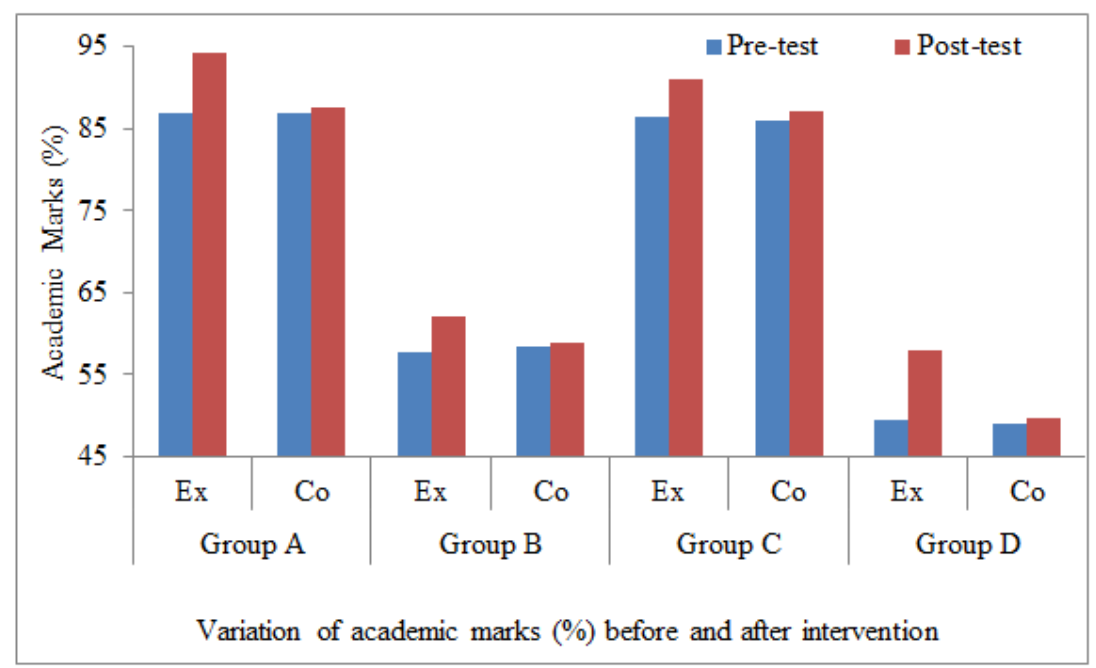

Fig 4: Variation of academic marks $(\%)$ before and after intervention

Where Ex stands for Experimental Group and Co stands for Control Group

It is evident from the Table 6 that the marks of the subjects in experimental Group A was 87 in the pretest which inclined to 94.15 after the intervention. The difference was found to be significant. Further, it was observed that the marks of the subjects in the control Group A was 87 that showed no significant change even after the intervention. Moreover, the intelligence quotient of the subjects in experimental Group B was 57.7 in the pretest which inclined to 62 after the intervention. The difference was found to be significant. Further, it was observed that the marks of the subjects in the control Group B was 58.5 that showed no significant change even after the intervention. Moreover, the intelligence quotient of the subjects in experimental Group $\mathrm{C}$ was 86.5 in the pretest which inclined to 91 after the intervention. The difference was found to be significant. Further, it was observed that the marks of the subjects in the control Group $\mathrm{C}$ was 86 that showed no significant change even after the intervention. Moreover, the intelligence quotient of the subjects in experimental Group D was 49.5 in the pretest which inclined to 58 after the intervention. The difference was found to be significant. Further, it was observed that the marks of the subjects in the control Group D was 49 that showed no significant change even after the intervention.

Inevitably, it is an undeniable fact that guidance is important for children to bring out the best 
in children. Of course, young minds need guidance to redeem their performance. Through guidance, children are given advice on how to manage and deal with academic, emotional, conflict and personal problems. Gerler and Anderson (1986) explain that the classroom guidance affects children's success in school. The students are advised on how to cope with different situations they tend to face in their school life. For instance, how should they talk politely or relate with their peers. This advice will give them perspective on how should they behave in certain scenarios. Proper guidance helps them to achieve their goals. In similar study, Borders and Drury (1992) have also emphasized comprehensive school guidance and counseling programs. Students get comprehensive advice on career, courses and jobs that enable them to make a proper and informed choice and understand what they can do after they are done with school. It allows students to talk to teachers about various experiences that make them uncomfortable. They can openly share problems that they cannot share with their parents. Brigman and Campbell (2003) endorse that the proper guidance along with teaching through the natural learning style of students will help them to enhance performance and prepare for life. It also helps students improve academic achievement and school success. Further, Schmidt (2003) also endorsed that guidance and counseling in schools is an essential service to let students learn how to live in peace and harmony with others in the school community. It also helps to bridge the gap between students and the school administration. Sink (2005) concurs that the guidance and counselling programs along with learning aids complementing the learner, improve the academic achievement among students. It enables students undergoing certain difficulties in their lives, to ask questions and clarify them through such sessions. School going children face stress being forced to perform better. Young and Kaffenberger (2011) believe that guidance and counselling make students better human beings since they learn how to act and behave in a particular situation. It also enhance their academic achievement and performance. The results are definitely supported by Carvalho et al., (2014) according to whom the educational guidance is a desired factor in school contexts. If the students are given proper guidance on how to deal with psychological problems affecting their studies, they will be able to develop problem-solving skills which would help them deal with such issues.

\section{CONCLUSION}

With this concern, it was found that when students are taught according to their inherent primary learning style, they can learn in an effective manner and the performance is higher as compared to the system where they are taught in the same traditional way. It was further observed that with the regular intervention of customized education and guidance, the interest of the students was developed in studies. The intelligence quotient, focus factor, decision making ability surged dramatically after the successful implementation of intervention program. Through the research study, it was inferred that the interest of the students developed in studies who received education through the methods linking directly to their strength and dominant learning style. Hence, the present research study underlines the effectiveness of teaching learning process that corresponds to each student's natural learning style.

The interventions motivated the children to learn, to remember things that they learn and to solve different problems.

\section{ACKNOWLEDGEMENTS}

The authors are thankful to the administration and students of Yadavindra Public School (YPS), Patiala, Punjab, India.

\section{REFERENCES}

- Alexander, R. J. (2001). Culture and pedagogy: International comparisons in primary education. Singapore: Blackwell publishing.

- Barros, J. A., Yantha, Z. D., Carter, M. J., Hussien, J., \& Ste-Marie, D. M. (2019). Examining the impact of error estimation on the effects of selfcontrolled feedback. Human movement science, 63 , 182-198.

- $\quad$ Bas, G., \& Beyhab, O. (2017). Effects of multiple intelligences supported project-based learning on students' achievement levels and attitudes towards English lesson. International Electronic Journal of Elementary Education, 2(3), 365-386.

- Blagg, N. (2012). Can we teach intelligence?: A comprehensive evaluation of Feuerstein's Instrumental Enrichment programme. New York: Routledge.

- Borders, L. D., \& Drury, S. M. (1992). Comprehensive school counseling programs: A review for policymakers and practitioners. Journal of Counseling \& Development, 70(4), 487-498.

- Boylan, H. R. (2009). Targeted Intervention for Developmental Education Students (TIDES). Journal of Developmental Education, 32(3), 14.

- Brigman, G., \& Campbell, C. (2003). Helping students improve academic achievement and school success behavior. Professional School Counseling, 7(2), 91-98.

- Carvalho, C., Martins, D., Santana, L. E., \& Feliciano, L. (2014). Teacher feedback: Educational guidance in different school contexts. Procedia-Social and Behavioral Sciences, 159, 219-223.

- Cassidy, S., Roche, B., \& Hayes, S. C. (2011). A relational frame training intervention to raise intelligence quotients: A pilot study. The Psychological Record, 61(2), 173-198.

- Derakhshan, A., \& Faribi, M. (2015). Multiple intelligences: Language learning and 
Jagriti Mehta et al., J Adv Educ Philos, Jan, 2022; 6(1): 37-44

teaching. International Journal of English Linguistics, 5(4), 63-72.

- Francis, R. (2012). Multiple Intelligence Approach to Curriculum Transaction in Achieving the Educational Objectives at Secondary School Level. Ph.D. thesis, University of Mumbai.

- Gardner, H. (2017). Taking a multiple intelligences (MI) perspective. Behavioral and Brain Sciences, 40, 30-31.

- Gerler Jr, E. R., \& Anderson, R. F. (1986). The effects of classroom guidance on children's success in school. Journal of Counseling \& Development, 65(2), 78-81.

- Greenman, N. P. (2005). Anthropology applied to education. In S. Kedia \& J. V. Willigen (Eds.), Applied anthropology: Domains of application (pp.263-306). United States of America: Praeger Publisher.

- Hall, J. (2018). Instruction: The Disposition to Be Creative. In The It Factor: What Makes a Teacher Great? (pp. 92-97). Boston: Brill Sense.

- Henze, R. (2020). Anthropology of education. Retrieved from https://doi.org/10.1093/acrefore/9780190854584.01 3.10

- Howard, G. (1983). Frames of mind: The theory of multiple intelligences. NY: Basics.

- James, E. (1987). The public/private division of responsibility for education: an international comparison. Economics of Education Review, 6(1), $1-14$.

- Jung, J. H., \& Chang, D. R. (2017). Types of creativity-Fostering multiple intelligences in design convergence talents. Thinking Skills and Creativity, 23, 101-111.

- Kerry, T. (2015). Learning, cognition and crosscurricular teaching. In Cross-Curricular Teaching in the Primary School (pp. 50-64). Routledge.

- Krannich, M., Goetz, T., Lipnevich, A. A., Bieg, M., Roos, A. L., Becker, E. S., \& Morger, V. (2019). Being over-or underchallenged in class: Effects on students' career aspirations via academic self-concept and boredom. Learning and Individual Differences, 69, 206-218.

- Kruger, J., \& Dunning, D. (1999). Unskilled and unaware of it: how difficulties in recognizing one's own incompetence lead to inflated selfassessments. Journal of personality and social psychology, 77(6), 1121.

- Kupers, E., Lehmann-Wermser, A., McPherson, G., \& Van Geert, P. (2019). Children's creativity:
A theoretical framework and systematic review. Review of Educational Research, 89(1), 93124.

- Lunenburg, F. C., \& Lunenburg, M. R. (2014). Applying Multiple Intelligences in the Classroom: A Fresh Look at Teaching Writing. International journal of scholarly academic intellectual diversity, 16(1).

- Morewedge, C. K., Yoon, H., Scopelliti, I., Symborski, C. W., Korris, J. H., \& Kassam, K. S. (2015). Debiasing decisions: Improved decision making with a single training intervention. Policy Insights from the Behavioral and Brain Sciences, 2(1), 129-140.

- Marwaha, S., \& Seth, G. (2017). Ascertaining Concurrent Validity \& Reliability of 'Multiple Intelligence Level Scale' to trace Multiple Intelligence Level of subjects. International Journal of Advanced Multidisciplinary Research. 4(4): 32-39.

- $\quad$ Nanda, H. K., Marwaha, S., \& Chawla, P. (2015). Development, Item Analysis, Standardization, Review and Expansion of the Cognitive Ability Test for a Wider Age Range (7-16 Years) on a Single Test. International Journal of Multidisciplinary Research and Development, 2(9), 334-350.

- Pritchard, A. (2013). Ways of learning: Learning theories and learning styles in the classroom. New York: Routledge.

- Schmidt, J. J. (2003). Counseling in schools: Essential services and comprehensive programs. United States: Allyn \& Bacon.

- Shearer, C. B., \& Karanian, J. M. (2017). The neuroscience of intelligence: Empirical support for the theory of multiple intelligences?. Trends in neuroscience and education, 6, 211-223.

- Siegler, R. S. (1983). Five generalizations about cognitive development. American Psychologist, 38(3), 263.

- Sink, C. A. (2005). Comprehensive school counseling programs and academic achievementA rejoinder to Brown and Trusty. Professional School Counseling, 9(1), 9-12.

- Toffler, A. (1972). The futurists. New York: Random House.

- Young, A., \& Kaffenberger, C. (2011). The beliefs and practices of school counselors who use data to implement comprehensive school counseling programs. Professional School Counseling, 15(2), 67-76. 